\title{
Epidemiology of Myocardial Infarction Caused by Presumed Paradoxical Embolism via a Patent Foramen Ovale
}

\author{
Franz X. Kleber, PhD; Telse Hauschild, MD; Antonia Schulz, MD; \\ Anne Winkelmann, MD; Leonhard Bruch, MD
}

\begin{abstract}
Background: Despite several negative prospective randomized trials on the efficacy of patent foramen ovale (PFO) occlusion, the discussion on indications is ongoing. Because the incidence of paradoxical coronary embolism through a PFO is unknown, we investigated the risk of paradoxical embolic myocardial infarction over a period of 13 years.
\end{abstract}

\begin{abstract}
Methods and Results: We conducted a retrospective and a prospective study. In the former, we searched the hospital database of a tertiary referral center for cases of acute myocardial infarction (AMI) during the past 10 years and screened them for possible paradoxical Mls. On this basis we started a prospective evaluation over 39 months in another tertiary referral center. All patients with AMI and normal coronary arteries were screened for PFO and if no other reason for the AMI could be found, the case was judged as presumed paradoxical embolism. In the retrospective analysis we found 22 cases $(0.45 \%)$ of presumed paradoxical coronary artery embolism under 4,848 AMI. In the prospective study there were 11 presumed paradoxical coronary artery embolisms among 1,654 patients with $\mathrm{AMI}$, representing an incidence of $0.67 \%$.
\end{abstract}

Conclusions: Our findings demonstrated that well below $1 \%$ of AMls are caused by paradoxical embolism via an interatrial communication. Although this percentage appears low, it is not a negligible number of patients based on the huge number of Mls occurring in the industrialized world.

Key Words: Myocardial infarction; Paradoxical embolism; Patent foramen ovale

A patent foramen ovale (PFO) is caused by defective fusion of the septum primum coverage of the fossa ovalis area after birth. A PFO is present in approximately $25 \%$ of the general population. ${ }^{1}$ In most cases it never leads to any health issues, but PFO has been recognized as a possible source of paradoxical (venoarterial) embolism since the late $18^{\text {th }}$ century, ${ }^{2}$ especially in patients with additional risk factors such as large right-to-left shunt, ${ }^{3}$ atrial septal aneurysm, ${ }^{4-7}$ thrombophilia ${ }^{8-11}$ or prominent Eustachian valve. ${ }^{12} \mathrm{~A}$ possible mechanism for PFO-related systemic embolic events is paradoxical embolism from the peripheral venous system ${ }^{13-17}$ through the interatrial communication to the systemic circulation. The embolisms have a preference to be transmitted to vascular areas in accordance with the anatomy and the centrifugal force (i.e., primarily into the cerebral arteries and there to the posterior vessels).$^{18}$ There are a few small studies and case reports that have reported paradoxical embolism to the non-cerebral circulation causing limb ischemia, splanchnic ischemia, and splenic or renal infarction. ${ }^{19-28}$

Almost exclusively the case reports suggest suspected paradoxical embolism as the reason for acute myocardial infarction (AMI) in patients with PFO and normal coronary arteries. ${ }^{26,28} 47$ Even fatal outcomes have been convincingly published. ${ }^{48,49}$ However, to date there has not been a large scale evaluation of this phenomenon.

\section{Methods}

Our approach to describing the epidemiology of AMI included a retrospective and a prospective study. We retrospectively analyzed the incidence over 10 years of paradoxical coronary embolism in a tertiary care center and then prospectively undertook an effort to prove this using the same criteria over 39 months in another tertiary care center.

\section{Retrospective and Prospective Studies}

For the retrospective study, we searched the database of the hospital's information system over a period of 10 years for cases of MI according to the International Classification of Diseases, searching for AMI, recurrent MI, and acute as well as silent ischemia. Subsequently all angiogram

Received October 26, 2016; revised manuscript received March 20, 2017; accepted April 3, 2017; released online April 27, 2017 Time for primary review: 5 days

Cardio Centrum Berlin Academic Teaching Institution, Charité University Medicine Berlin, Berlin (F.X.K., A.S.); Ernst von Bergmann Klinikum Potsdam, Academic Teaching Hospital, Charité University Medicine Berlin, Potsdam (T.H.); and Unfallkrankenhaus Berlin, Academic Teaching Hospital, Charité University Medicine Berlin, Berlin (A.W., L.B.), Germany

The first two authors contributed equally to this work (F.X.K., T.H.).

Mailing address: Franz X. Kleber, MD, FESC, Professor of Medicine, Cardio Centrum Berlin, Academic Teaching Institution, Charité Universitätsmedizin Berlin, Unter den Linden 21, Berlin 10117, Germany. E-mails: fxkleber@gmx.eu

ISSN-1346-9843 All rights are reserved to the Japanese Circulation Society. For permissions, please e-mail: cj@j-circ.or.jp 
reports were screened for patients showing otherwise normal (i.e., non-atherosclerotic) coronary arteries. Even mild coronary stenoses (e.g., $\geq 25 \%$ than minimal wall irregularities) have led to exclusion of patients. Hospital records were used to identify patients with proven PFO and to exclude all patients with other known risk factors (see below). Thus we evaluated the percentage of patients with presumed paradoxical embolism caused by PFO of the total subset of patients treated for AMI. We also evaluated the percentage of PFO closures for paradoxical MI among all patients with interventional PFO closure.

Our second step was to prospectively investigate the presence of suspected paradoxical coronary embolism in all cases of AMI presenting at a different hospital over 39 months.

\section{Schedule for the Retrospective Study}

Step 1: search hospital information system for all patients with a discharge diagnosis of MI.

Step 2: retrospectively search catheter laboratory database for patients with normal coronary angiogram and angiographic or clinical and enzymatic evidence of MI.

Step 3: search catheter laboratory database for patients with PFO.

Step 4: search hospital information database for patients with PFO.

Step 5: extract all records for patients with normal coronary arteries, PFO and presumed paradoxicalembolic MI according to the designated criteria (see below).

\section{Schedule for the Prospective Study}

Step 1: prospectively enter patients with PFO, normal coronary arteries and presumed paradoxical embolism (see criteria below) into a database for PFO.

Step 2: search hospital information system for total number of patients with discharge diagnosis of MI.

Step 3: calculate the percentage of patients in Step 1 to those in Step 2.

Figure 1 summarizes the overall study design.

\section{Diagnostic Criteria}

For both studies the same criteria for diagnosis of presumed paradoxical embolism through a PFO were used:

All patients with AMI according to ECG criteria and elevation of cardiac troponin or creatine kinase who had angiographically normal coronary arteries were screened for interatrial connection and additional risk factors for systemic emboli (i.e., atrial septal aneurysm (ASA) and Eustachian valve).

The screening was performed with a HP SONOS echocardiography system (Hewlett-Packard, Palo Alto, CA, USA) or a Philips IE 33 (Philips Healthcare, Eindhoven, The Netherlands) with a multiplane transesophageal probe. The transthoracic studies were performed with 4- or 8-MHz transducers and second harmonic imaging. In addition to standard transthoracic imaging, transesophageal contrast echocardiography (TEE) was performed to visualize the interatrial septum, test for a right-to-left shunt using the Valsalva maneuver, and exclude thrombi, especially in the left atrial appendage, or other structural abnormalities. The contrast agent used was mostly Echovist (Schering AG Berlin, Germany); later, also agitated saline. The criteria of an ASA diagnosed by TEE included a diameter at

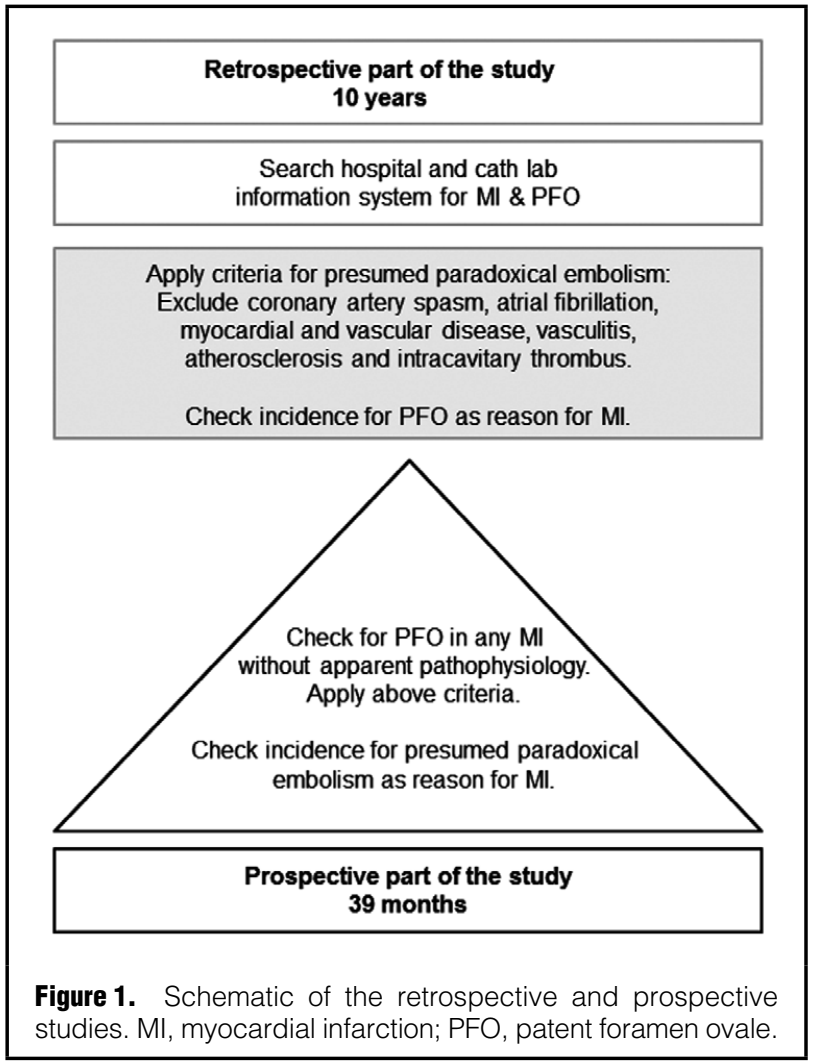

the base $\geq 15 \mathrm{~mm}$ and an excursion with an amplitude $\geq 15 \mathrm{~mm}$. A PFO was defined as the appearance of microbubbles across the interatrial septum (with or without the Valsalva maneuver) after intravenous contrast injection and the absence of a color Doppler jet, indicating a left-toright shunt. If, in addition to the right-to-left shunt during contrast injection, a left-to-right shunt was seen on color Doppler, the defect was defined as an ASD. If there was typical PFO morphology without a visible interatrial septal gap, the defect was defined as a PFO-like ASD.

If no other reason for the AMI could be found, the case was judged as presumed paradoxical embolism.

The following items had to be excluded: coronary artery spasm caused by intracoronary testing with acetylcholine (urinary testing of cocaine use if clinically indicated); paroxysmal or persistent atrial fibrillation by at least 24 hours of Holter monitoring; valvular heart disease on echocardiography; vasculitis or collagen vascular disease by history and screening tests as appropriate; atherosclerotic disease of the carotid arteries, the aortic arch (by ultrasound investigation, MRI or CT angiography) or the coronary arteries (by coronary angiography); clinical signs or symptoms of peripheral vascular disease; major ventricular dysfunction or clinical heart failure independent of the acute event; LVthrombus (by echocardiography).

\section{PFO Closure}

Interventional closure of the interatrial communication was offered to all patients if a PFO, PFO-like ASD, or an ASD with or without ASA was confirmed by TEE and no other cause for systemic thromboembolism and no local arterial disease were found.

To identify possible risk factors for paradoxical MI we compared the characteristics of patients with paradoxical 

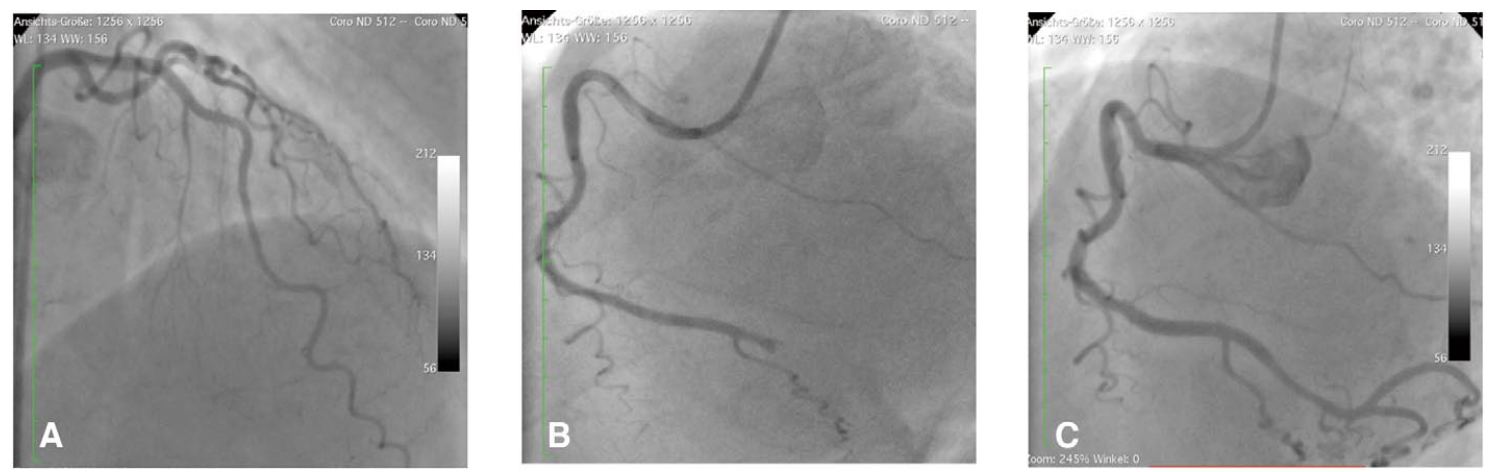

Figure 2. Angiograms from a case of paradoxical embolic myocardial infarction in a 50-year-old female patient with a PFO of $13 \mathrm{~mm}$, atrial septal aneurysm and prominent Eustachian valve. The angiograms show a normal left coronary artery $(\mathbf{A})$ and a thrombus occluding the posterolateral branch of the right coronary artery before (B) and after recanalization (C). PFO, patent foramen ovale.

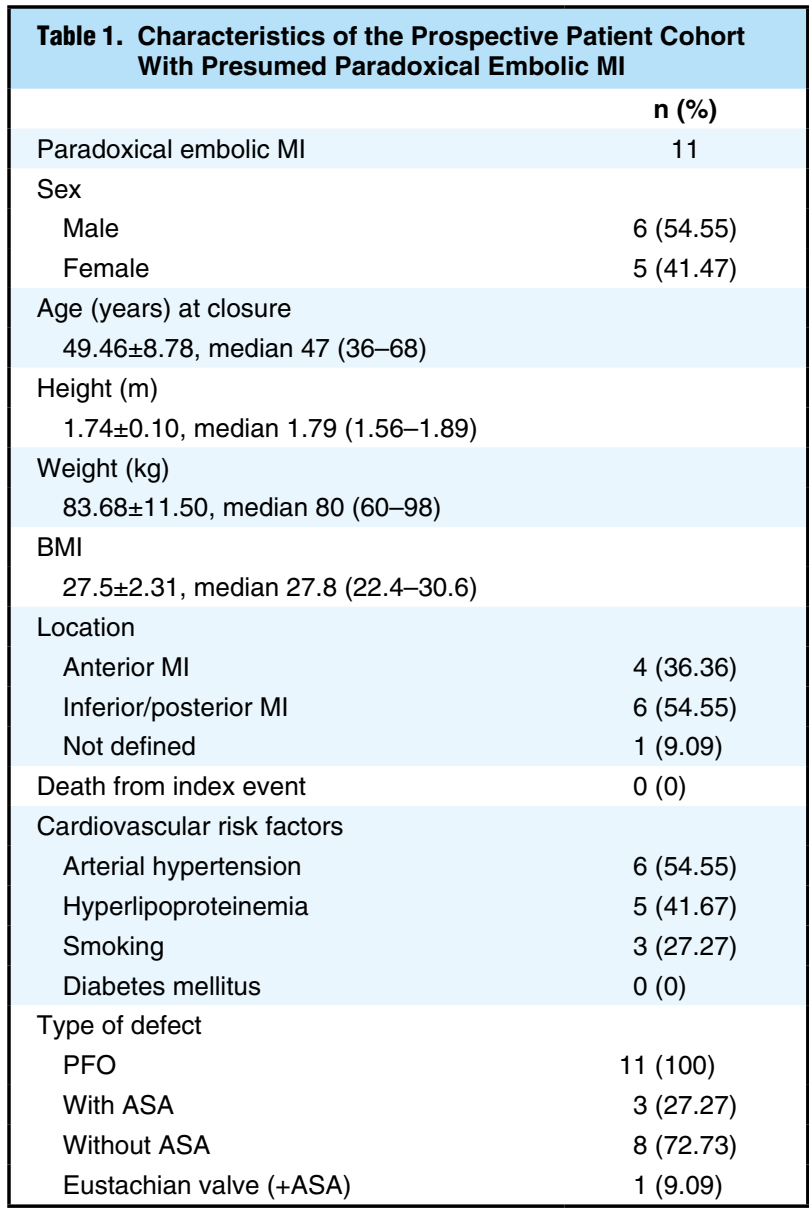

ASA, atrial septal aneurysm; BMI, body mass index; MI, myocardial infarction; PFO, patent foramen ovale.

AMI with those of patients who underwent PFO closure for any indication within the same 39-month period.

Our work-up for PFO patients has been published previously. ${ }^{50-52}$ All patients gave written informed consent before the implantation procedure. This study was presented to the authorized ethical committee of Charite University Medicine Berlin and permission was granted under number EA1/409/16.

\section{Results}

\section{Retrospective Study}

Between 1 January 1998 and 31 December 2007, a 10-year period, 4,848 cases of MI were treated. The mean age of the patient population was $63.2 \pm 12.7$ years (range 18 -95 years); 22 patients were identified as having presumed paradoxical embolism (mean age $43.0 \pm 12.0$ years, range 18-68), representing $0.45 \%$ of the overall AMIs (16 of this patient population have been mentioned in our previous publications describing the likelihood of recurrences of paradoxical venoarterial embolism after PFO occlusion). ${ }^{50-52}$

\section{Prospective Study}

Based on the retrospective study results, we prospectively studied the incidence of presumed paradoxical MI in a patient population in another tertiary referral center over a period of 39 months. Between 1 January 2009 and 31 March 2012, 1,654 patients were treated for MI. The average age of these patients (1,073 male, 581 female) was $69.3 \pm 3.4$ years. We identified 11 patients with a presumed paradoxical embolic pathogenesis, representing an incidence of $0.67 \%$ of the overall AMIs. Figure 2 shows the angiograms of a typical case of presumed paradoxical embolic MI.

Patient and lesion characteristics of presumed paradoxical embolic myocardial infarctions are presented in Table 1 (prospective cohort) and Table 2 (combined prospective and retrospective cohorts).

\section{Discussion}

Venoarterial embolism has been described in various settings, including stroke, ${ }^{7}$ peripheral embolism, spleen, kidney and intestinal embolisms, ${ }^{19-27}$ gas bubble embolism in divers, ${ }^{53}$ and others. Although the flow distribution in the aortic arch preferences the cerebral and especially the posterior cerebral circulation, ${ }^{18}$ an embolism from the heart can principally go to any vascular territory. Thus it is not 
surprising that we also found a subset of patients with MI caused by this pathophysiology. Hitherto, mainly case reports have pointed out that MI can be caused by emboli through a PFO, and associations with thrombophilia, pulmonary embolism (PE) and stroke have been reported. 29,31,32,35-38 Overall, nearly 60 cases have been reported in the literature.

Among 6,502 patients with AMI, we found $33(0.51 \%)$ with presumed paradoxical embolism as the most likely pathophysiology. In the prospective study, the percentage was somewhat higher $(0.67 \%)$ than in the retrospective series $(0.45 \%)$, but there was no substantial difference. Although this percentage is low and does not make the presence of a PFO a major risk factor for MI, it is not negligible on the basis of the huge numbers of MIs occurring in the industrialized word. Based on an estimate of approximately 7 million MIs worldwide per year, there would be a case load of at least 35,000 cases of MI caused by paradoxical coronary embolism or, based on an estimated annual incidence of roughly $200 \mathrm{MIs} / 100.000$ population, an incidence of at least 10 cases per million of the population. ${ }^{54}$

As in our earlier series of PFO occlusion for cerebral embolism, we found a rather large average PFO, being over $10 \mathrm{~mm}$ on average. ${ }^{50,52}$ The importance of PFO resp. shunt size is underscored by the sizable subset of patients with ASA, ASD or a PFO morphology with bidirectional shunt ("PFO-like ASD"). These features have also been described as risk factors for paradoxical cerebral embolism in patients with PFO. 3,4

The distribution of the location of MI was almost even between anterior and non-anterior. However, a large subset of more than one-third of the patients had had other arterial embolic events or PE before, corroborating the presumed paradoxical embolic pathogenesis.

Although the percentage of patients with diabetes was much lower than in most series of patients with MI, other risk factors such as hypertension and dyslipidemia were found in high percentages, albeit lower than in typical MI patients. Patients, however, were much younger (45.7 years vs. 63.2 and 69.3 years in the 2 MI cohorts) than patients with atherosclerotic disease. Overall, the characteristics of the patients with MI compared well with those of patients in whom a PFO was occluded for presumed paradoxical brain embolism.

A detailed search for the rate of MI among patients treated with a PFO occluder for other reasons has not been done. Dao and Tobis reported 1.9\% MIs among their indications for PFO occlusion, ${ }^{26}$ a percentage somewhat lower than found by us $(5.4 \%$ in the 1 st and $17.7 \%$ in the 2 nd series, data not shown) in our first series. In our second, prospective series of PFO occlusions, however, we found $17.7 \% \mathrm{MI}$ indications (data not shown) among the PFO occlusions. However, Wöhrle et al also found a $10.8 \%$ incidence of presumed MI scars in patients with a first cryptogenic stroke in their MRI late gadolinium enhancement analyses including clinically unapparent MIs. ${ }^{38}$

The prevalence of PFO in patients with MI has not been extensively investigated. Crump et al reported no increased prevalence of PFO in a small series of patients with MI and normal coronary arteries. ${ }^{40}$ Given the low incidence of paradoxical embolic events in both of our series, it is unlikely that patients with MI have an excessively high incidence of PFO.

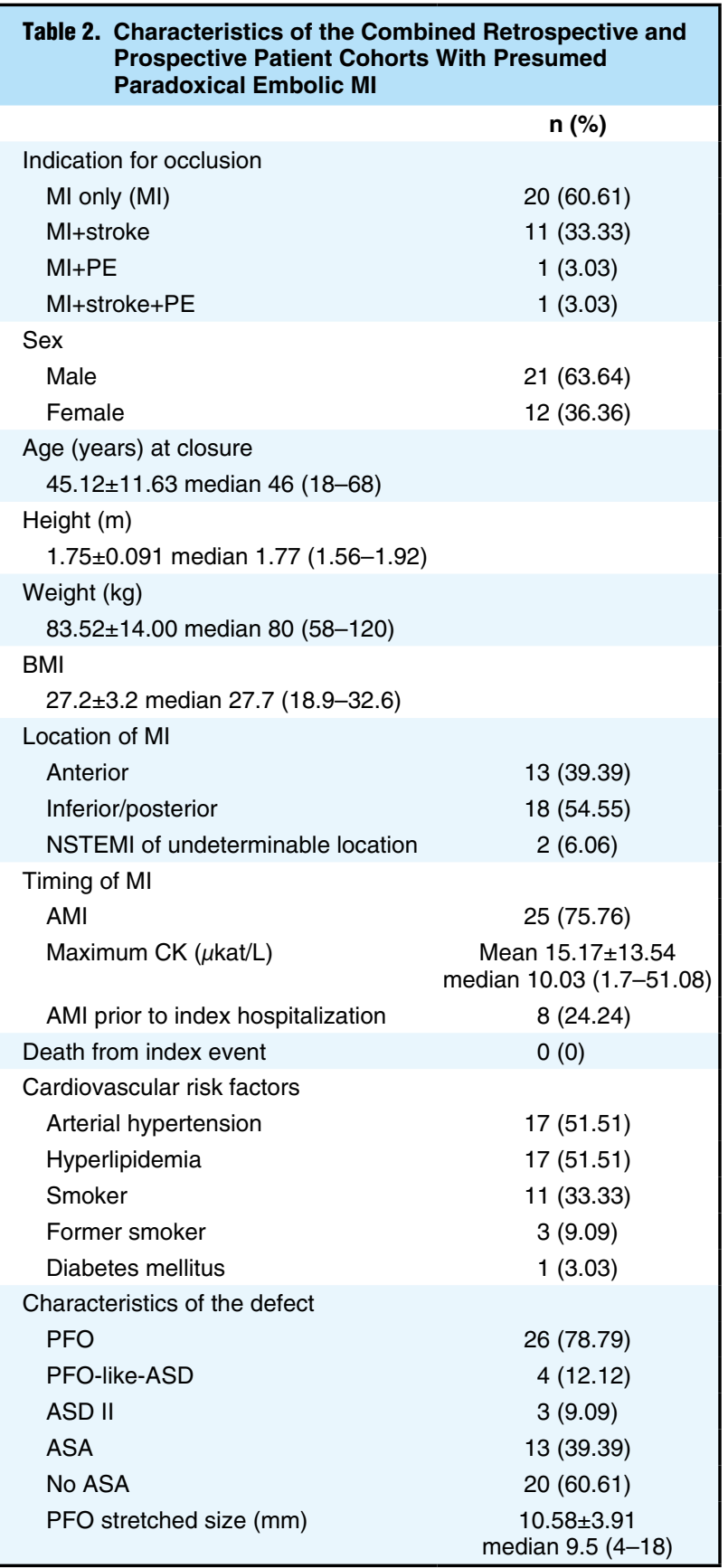

AMI, acute myocardial infarction; ASD, atrial septal defect; NSTEMI, non-ST-elevation MI; PE, pulmonary embolism; TIA, transient ischemic attack. Other abbreviations as in Table 1.

\section{Study Limitations}

Overall, our approach to assessing prevalence was conservative. In particular, the exclusion of patients with atherosclerosis impedes evaluation of paradoxical embolism in patients with competing pathophysiologies. It is conceivable that these patients might have an even higher incidence, because thromboembolism in general increases with age and disease burden. Moreover, adjudication of thromboembolic MI has been apparently missed repeatedly in the literature. ${ }^{55,56}$

Although the PFO etiology is mainly found among patients with MI and normal coronary arteries, it cannot 
be excluded that patients with arteriosclerotic heart disease also have paradoxical embolism. Furthermore, thrombotic occlusions caused by atherothrombosis can be difficult to distinguish angiographically from arterial embolism. Our strict exclusion of patients with arteriosclerotic disease from the PFO program might have led to an underestimation of this pathophysiology. However, it is apparent from our results that $\mathrm{PFO}$ does not play a negligible role in the pathogenesis of AMI. Again, not excluding these patients would have meant us being unable us to say that, at least, the incidence found was because of paradoxical embolism and PFO. Therefore, we believe that the effort put into this large series of patients was worthwhile to describe this pathological entity in depth.

Vice versa MI with normal coronaries has been reported in $1-8.5 \%$ of patients and can have a variety of other pathophysiologies. ${ }^{\mathbf{4 1}-\mathbf{4 7}}$ Coronary artery spasm has been described in $6.6-15.5 \%,{ }^{\mathbf{4 5}, 47}$ hypercoagulability (including use of contraceptives) in $13 \%,{ }^{47}$ collagen vascular diseases with vasculitis in 2\% (47), peri-/myocarditis in $27-29 \%, \mathbf{4 3 , 4 4}$ takotsubo cardiomyopathy in $5 \% \mathbf{4 3}$ and paradoxical embolism in $2 \% .{ }^{\mathbf{4 2}, \mathbf{4 3}, \mathbf{4 6}} \mathrm{We}$ did not follow up the patients in our series who were not found to have a PFO.

Nevertheless, other pathophysiologies that might mimic paradoxical embolism have to be considered and in some cases might have been a competing explanation for the MI. Among these are especially coronary artery vasospasm and takotsubo disease.

We searched for vasospasm in all patients with a history of chest pain and normal coronary arteries by testing with intracoronary acetylcholine. Thus, vasospasm as reason for MI is unlikely, but temporary spasm induced by components of the diet or drugs cannot be completely excluded. Takotsubo leads to apical or non-apical wall motion abnormalities that usually do not follow a coronary distribution pattern. None of our patients had an atypical wall motion abnormality pointing to takotsubo, but as coronary spasm is one of the discussed pathophysiologies of this syndrome, it cannot be completely excluded that some patients had had takotsubo.

Rare episodes of atrial fibrillation are difficult to detect and this might have led to an overestimation of the PFOassociated MI pathomechanism. However, the almost complete exclusion of patients with other heart disease makes atherothrombotic and embolic reasons less likely even in the presence of paroxysmal atrial fibrillation.

We undoubtedly underestimated the likelihood of paradoxical MI by excluding patients with atherosclerosis, who are generally more sick, older and more prone to thrombosis and PE, and thus also to paradoxical embolism. In a large population study Sørensen et al found among almost 17,000 patients with $\mathrm{PE}$ a relative risk of 2.6 for stroke or MI vs. a normal control population of 163,000 patients. ${ }^{57}$ However, they concluded it was not plausible that PE in itself causes MI and apparently completely disregarded a paradoxical embolic pathophysiology. Therefore, we consider our study an "eye opener" for those who think similarly and we tried to prove the occurrence of paradoxical embolic MI in a population in which all other plausible causes were excluded with unusual scrutiny.

Overall, the likelihood that the events were caused by paradoxical coronary embolism is underscored by the high percentage of patients who also showed other arterial embolisms and by the large size of the PFO.

\section{Conclusion}

Our findings demonstrated that less than 1\% of MIs were caused by paradoxical embolism via an interatrial communication. Based on an estimate of approximately 7 million MIs worldwide per year there would be an expected case load of at least 35,000 cases of MI caused by paradoxical coronary embolism or, based on an estimated annual incidence of roughly $200 \mathrm{MIs} / 100.000$ population, ${ }^{\mathbf{5 4}}$ an incidence of at least 10 cases per million of the population.

\section{Disclosures}

The authors declare no conflictS of interest. There was no funding of the study.

\section{References}

1. Hagen PT, Scholz DG, Edwards WD. Incidence and size of patent foramen ovale during the first 10 decades of life: An autopsy study of 965 normal hearts. Mayo Clin Proc 1984; 59: $17-20$.

2. Cohnheim J. Thrombose und Embolie. In: Vorlesung über allgemeine Pathologie, Vol. 1. Berlin, Hirschwald, 1877; 134.

3. Lamy C, Giannesini C, Zuber M, Arquizan C, Meder JF, Trystram D, et al. Clinical and imaging findings in cryptogenic stroke patients with or without patent foramen ovale: The PFOASA Study. Stroke 2002; 33: 706-711.

4. Mügge A, Daniel WG, Angermann C, Spes C, Khandheria BK, Kronzon I, et al. Atrial septal aneurysm in adult patients: A multicenter study using transthoracic and transesophageal echocardiography. Circulation 1995; 91: 2785-2792.

5. Cabanes L, Mas JL, Cohen A, Amarenco P, Cabanes PA, Oubary P, et al. Atrial septal aneurysm and patent foramen ovale as risk factors for cryptogenic stroke in patients less than 55 years of age: A study using transesophageal echocardiography. Stroke 1993; 24: $1865-1873$.

6. Stone DA, Godard J, Corretti MC, Kittner SJ, Sample C, Price TR, et al. Patent foramen ovale: Association between the degree of shunt by contrast transesophageal echocardiography and the risk of future ischemic neurologic events. Am Heart J 1996; 131: 158-161.

7. Mas JL, Zuber M. Recurrent cerebrovascular events in patients with patent foramen ovale, atrial septal aneurysm, or both and cryptogenic stroke or transient ischemic attack: French Study Group on Patent Foramen Ovale and Atrial Septal Aneurysm. Am Heart J 1995; 130: 1083-1088.

8. Karttunen V, Hiltunen L, Rasi V, Vahtera E, Hillbom M. Factor $\mathrm{V}$ Leiden and prothrombin gene mutation may predispose to paradoxical embolism in subjets with patent foramen ovale. Blood Coagul Fibrinolysis 2003; 14: 261 - 268.

9. Botto N, Spadoni I, Giusti S, Ait-Ali L, Sicari R, Andreassi MG. Prothrombotic mutations as risk factors for cryptogenic ischemic cerebrovascular events in young subjects with patent foramen ovale. Stroke 2007; 38: 2070-2073.

10. Lichy C, Reuner KH, Buggle F, Litfin F, Rickmann H, Kunze A, et al. Prothrombin G20210A mutation, but not factor V Leiden, is a risk factor in patients with persistent foramen ovale and otherwise unexplained cerebral ischemia. Cerebrovasc Dis 2003; 16: $83-87$.

11. Giardini A, Donti A, Formigari R, Bronzetti G, Prandstraller D, Bonvicini $\mathrm{M}$, et al. Comparison of results of percutaneous closure of patent foramen ovale for paradoxical embolism in patients with versus without thrombophilia. Am J Cardiol 2004; 94: $1012-1016$.

12. Schuchlenz HW, Saurer G, Weihs W, Rehak P. Persisting eustachian Valve in Adults: Relation to patent foramen ovale and cerebrovascular events. J Am Soc Echocardiogr 2004; 17: 231 233.

13. Ranoux D, Cohen A, Cabanes L, Amarenco P, Bousser MG, Mas JL. Patent Foramen ovale: Is stroke due to paradoxical embolism? Stroke 1993; 24: 31-34.

14. Lechat P, Mas JL, Lascault G, Loron P, Theard M, Klimczac M, et al. Prevalence of patent foramen ovale in patients with stroke. N Engl J Med 1988; 318: 1148-1152.

15. Webster MW, Chancellor AM, Smith HJ, Swift DL, Sharpe DN, Bass NM, et al. Patent foramen ovale in young stroke patients. 
Lancet 1988; 2: 11-12.

16. DiTullio M, Sacco RL, Gopal A, Mohr J P, Homma S. Patent foramen ovale as a risk factor for cryptogenic stroke. Ann Intern Med 1992; 117: 461-465.

17. Bogousslavsky J, Garazi S, Jeanrenaud X, Aebischer N, Van Melle G. Stroke recurrence in patients with a patent foramen ovale: The Lausanne study [Lausanne Stroke with Paradoxical Embolism Study Group]. Neurology 1996; 46: 1301-1305.

18. Yasaka M, Otsubo R, Oe H, Minematsu K. Is stroke a paradoxical embolism in patients with patent foramen ovale? Intern Med 2005; 44: 434-438

19. Kouskov OS, Nichols DJ, O'Hearn DJ. Paradoxical arterial embolism involving both upper extremities in a patient with pulmonary embolism and a patent foramen ovale. Clin Appl Thromb Hemost 2011; 17: E98-E101.

20. Miller S, Causey MW, Schachter D, Andersen CA, Singh N. A case of limb ischemia secondary to paradoxical embolism. Vasc Endovasc Surg 2010; 44: 604-608.

21. Shoeibi N, Poorzand H, Abrishami M. Branch retinal artery occlusion in a patient with patent foramen ovale. Ophthal Vis Res 2013; 8: $58-61$

22. Nara M, Komatsuda A, Fujishima M, Fujishima N, Nara M, Iino $\mathrm{T}$, et al. Renal paradoxical embolism in a hypertensive young adult without acute ischemic symptoms. Clin Exp Nephrol 2011; 15: 582-585.

23. Iwasaki M, Joki N, Tanaka Y, Hara H, Suzuki M, Hase H. A suspected case of paradoxical renal embolism through the patent foramen ovale. Clin Exp Nephrol 2011; 15: 147-150.

24. Ronco F, Rigatelli G, Dell'Avvocata F, Giordan M, Ronco C, Cardaioli P. Embolic renal infarct, patent foramen ovale and coronary artery dissection: A strange case of cardio-renal connection. Cardiovasc Revasc Med 2011; 12: 67.e5-e7.

25. Ministro A, Evangelista A, Damiã A, Dinis da Gama A. Recurrent systemic paradoxical embolism: A clinical report. Rev Port Circ Cardiothorac Vasc 2008; 15: 111-117.

26. Dao CN, Tobis JM. PFO and paradoxical embolism producing events other than stroke. Cathet Cardiovasc Interv 2011; 77: 903-909.

27. Parsi A, Wruck U, Bruch L, Grad O, Rux S, Krebs H, et al. Akute Darmischämie durch gekreuzte Embolisation bei persistierendem Foramen ovale. Cardio News 2000; 3: 4-5.

28. Rigatelli G, Giordan M, Braggion G, Aggio S, Chinaglia M, Zattoni $\mathrm{L}$, et al. Incidence of extracerebral paradoxical embolisms in patients with intracardiac shunts. Cardiovasc Revasc Med 2007; 8: $248-250$.

29. Grogono J, Fitzsimmons SJ, Shah BN, Rakhit DJ, Gray HH. Simultaneous myocardial infarction and ischaemic stroke secondary to paradoxical emboli through a patent foramen ovale. Clin Med 2012; 12: 391-392.

30. Feit A, Hazday MS, Reddy CVR, Kipperman R. Bilateral coronary thrombosis in the absence of inducible coronary spasm, thrombocytosis, coagulation abnormalities, or angiographic evidence of coronary artery disease: Previously undescribed method of myocardial infarction. Catheter Cardiovasc Diagn 1988; 15: $40-43$.

31. Croft AP, Khan JN, Chittari MV, Varma C. Paradoxical coronary artery embolism causing acute myocardial infarction in a young woman with factor V Leiden thrombophillia. $J R$ Coll Physicians Edinb 2012; 42: 218 -220.

32. Ferreira AR, Freitas A, Magno P, Soares AO, Farto e Abreu P, Neves JP, et al. Acute coronary syndrome of paradoxical origin. Rev Port Cardiol 2013; 32: 817-821.

33. Dietz DM, Cleveland JD, Chewning KG, Dent JM, Kern JA, Keeley EC. Impending paradoxical embolism presenting as myocardial infarction. J Cardiol Cases 2013; 7: e145-e148.

34. Ménager C, Bui HT, Rubin S, Nazeyrollas P, Metz D. Coronary embolism due to an adherent right atrium thrombus through a patent foramen ovale. Ann Cardiol Angiol 2013; 62: 438-441.

35. Hline A, Malik N, Khokhar A, Aggarwal R. Acute myocardial infarction caused by paradoxical embolism with concomitant pulmonary embolism. BMJ Case Rep, doi:10.1136/bcr.03.2011. 3953.

36. Ramineni R, Daniel GK. Association of a patent foramen ovale with myocardial infarction and pulmonary emboli in a peripartum woman. Am J Med Sci 2010; 340: 326-328.

37. Delvigne M, Vermeersch P, Van den Heuvel P. Thrombus-intransit causing paradoxical embolism in cerebral and coronary arterial circulation. Acta Cardiol 2004; 59: 669-672.

38. Wöhrle J, Kochs M, Hombach V, Merkle N. Prevalence of myocardial scar in patients with cryptogenic cerebral ischemic events and patent foramen ovale. JACC Cardiovasc Imaging 2010; 3: 833-839.

39. Mehan VK, Wahl A, Walpoth N, Meier B. Instant percutaneous closure of patent foramen ovale in patients with acute myocardial infarction and normal coronary arteries. Catheter Cardiovasc Interv 2006; 67: 279-282.

40. Crump R, Shandling AH, Van Natta B, Ellestad M. Prevalence of patent foramen ovale in patients with acute myocardial infarction and angiographically normal coronary arteries. Am J Cardiol 2000; 85: $1368-1370$

41. Alpert J. Myocardial infarction with angiographically normal coronary arteries. Arch Intern Med 1994; 154: 265-269.

42. Pasternack RC, Braunwald E, Sobel BE. Acute myocardial infarction. In: Heart disease, 3rd edn. Philadelphia: WB Saunders, 1988; $1222-1313$

43. Ahmar W, Lefkovits J. Acute ST elevation myocardial infarction with angiographically normal coronary arteries: Causes and outcomes. Int J Cardiol 2008; 128: 131-133.

44. Ammann P, Marshall S, Kraus M, Schmid L, Angehrn W, Krapf $\mathrm{R}$, et al. Characteristics and prognosis of myocardial infarction in patients with normal coronary arteries. Chest 2000; 117: $333-$ 338.

45. Germing A, Lindstaedt M, Ulrich S, Grewe P, Bojara W, Lawo $\mathrm{T}$, et al. Normal angiogram in acute coronary syndrome: Preangiographic risk stratification, angiographic findings and follow-up. Int $J$ Cardiol 2005; 99: 19-23.

46. Larsen AI, Galbraith PD, Ghali WA, Norris CM, Graham MM, Knudston ML. Characteristics and outcomes of patients with acute myocardial infarction and angiographically normal coronary arteries. Am J Cardiol 2005; 95: 261-263.

47. Da Costa A, Isaaz K, Faure E, Mourot S, Cerisier A, Lamaud M. Clinical characteristics, etiological factors and long-term prognosis of myocardial infarction with an absolutely normal coronary angiogram. Eur Heart J 2001; 22: 1459-1465.

48. Abecasis J, Ribeiras R, Gabriel HM, Andrade MJ. Thrombus entrapment: The clue for coronary embolism. Eur Heart $J$ 2014; 35: 2971.

49. Pavoni D, Zanuttini D, Spedicato L, Mazzaro E, Ugolino L. Large interatrial thrombus-in-transit resulting in acute myocardial infarction complicated by atrioventricular block and cardiogenic shock. J Am Coll Cardiol 2012; 59: 1329.

50. Bruch L, Parsi A, Grad MO, Rux S, Burmeister T, Krebs H, et al. Transcatheter closure of interatrial communications for secondary prevention of paradoxical embolism: Single-center experience. Circulation 2002; 105: 2845-2848.

51. Dubiel M, Bruch L, Liebner M, Schmehl I, Winkelmann A, Rux $\mathrm{S}$, et al. Exclusion of patients with arteriosclerosis reduces longterm recurrence rate of presumed arterial embolism after PFO closure. J Interv Cardiol 2007; 20: 275-281.

52. Dubiel M, Bruch L, Schmehl I, Liebner M, Winkelmann A, Stretz A, et al. Migraine headache relief after percutaneous transcatheter closure of interatrial communications. J Interv Cardiol 2008; 21: 32-37.

53. Torti SR, Billinger M, Schwerzmann M, Vogel R, Zbinden R, Windecker $\mathrm{S}$, et al. Risk of decompression illness among 230 divers in relation to the presence and size of patent foramen ovale. Eur Heart J 2004; 25: 1014-1020.

54. Steg PG, James SK, Atar D, Badano LP, Blömstrom-Lundqvist C, Borger MA, et al. Task Force on the Management of STsegment Elevation Acute Myocardial Infarction of the European Society of Cardiology (ESC): ESC Guidelines for the management of acute myocardial infarction in patients presenting with ST-segment elevation. Eur Heart J 2012; 33: 2569-2619.

55. Sürder D, Kucher N, Eberli FR, Roffi M. Intracoronary thrombus in a 26-year-old man. Eur Heart $J$ 2006; 27: 2631.

56. Sardar MR, Pieczynski LM, Saeed W, Domsky SM, Shapiro TA, Coady P. All at once: Multivessel spontaneous coronary artery dissection with right coronary artery ST-segment elevation myocardial infarction. JACC Cardiovasc Interv 2014; 7: e161e162.

57. Sørensen HT, Horvath-Puho E, Pedersen L, Baron JA, Prandoni $\mathrm{P}$. Venous thromboembolism and subsequent hospitalisation due to acute arterial cardiovascular events: A 20-year cohort study. Lancet 2007; 370: 1773-1779. 